\author{
Henryk Bałuch \\ prof. dr hab. inż. \\ Instytut Kolejnictwa \\ hbaluch@ikolej.pl

\section{Iwona Nowosińska} \\ mgr inż. \\ Instytut Kolejnictwa \\ inowosinska@ikolej.pl
}

DOI: 10.35117/A_ENG_16_04_04

\title{
Selected problems of forecasting geometric changes to railway superstructure
}

\begin{abstract}
Rationale expenditure for repairing superstructure and the opportunity to save the life cycle costs of superstructure are related with improving methods of planning repairs of railway tracks. An essential component of the planning superstructure repairs is forecasting its changes. The purpose of forecasting is to determine when and what kind of repair should be performed. The article presents the most important stages of forecasting changes in the geometry of superstructure and an introduction to the development of a harmonized method of forecasting. It draws attention to the problems and the complexity of the issue of forecasting changes in superstructure, which still requires a lot of research in the field of forecasting structural changes and changes in geometry.
\end{abstract}

Keywords: superstructure; forecasting; track geometry

\section{Introduction}

Improving planning repairs of railway superstructure is the subject of creative researches in many countries. Appropriate methods of planning are the possibility of saving costs of life cycle, with maintaining all of the requirements, to which the construction of superstructure should correspond. In planning repairs, especially with the limited expenditure, should be included elements enabling to use rankings as introduced in [3]. Criteria of repair order are also included in the studies [1,2].

An essential component of planning repairs superstructure is forecasting its changes, the aim of which is early determination at which date and scope the repair should be done in the coming periods. Forecasting is not necessary in relation to the tracks with exceeded terms of repairs.

A full superstructure forecast includes the geometric and structural condition. However, the superstructure repairs are performed most often due to exceeded limits of the geometric state. Forecasts can also refers to a narrow issues. An example of such issues in the construction of crossovers is forecast of failures of switch drives [6]. An example of the work, which considered only the geometric features of the superstructure, introducing 14 criteria (including four cases of deviations gauge) is presented in [5]. For such specific deviations, it was developed separate models as a function of load and the number of passing cars. For the assessment of risk, we used in this work a survival analysis taking as an survival no derailments between two successive derailments.

More important stages of forecasting for changes in geometric superstructure are:

- identification of the route or section of track covered by forecasting and selection of a similar section, 
- establishment of the measure of changes in the geometric track,

- specification of the method of forecasting and execution of calculations.

\section{Identification of the route and measure of the geometric state}

Each section of track, on which the changes (over time or load) are analysed should be clearly characterized. This characteristic should be updated after each cycle of forecasting.

Characteristics of track covering a trail or a long stretch with similar status include:

- the average value of the geometric measurement, e.g. a synthetic track status indicator $J$

$$
\bar{J}=\frac{1}{n} \sum_{i=1}^{n} J_{i}
$$

- unbiased standard deviation

$$
S_{J}=\left(\frac{1}{n-1} \sum_{1=1}^{n}\left(J_{i}-\bar{J}\right)^{2}\right)^{\frac{1}{2}}
$$

- the coefficient of variation, which is the average percentage variation of the studied feature

$$
V_{J}=100 \frac{S_{J}}{\bar{J}}
$$

- range of typical variation

$$
\vec{J}-S_{J} \quad \vec{J}+S_{J}
$$

The use of the unbiased standard deviation is justified by a relatively small number of kilometres of track on one trail. In the case of very short routes, standard deviation can be determined from the range using conversion factors [11].

The most common superstructure repairs are ongoing maintenance in the form of conquest and launching the track by conquer machine. A measure of the geometrical state superstructure may be already mentioned and generally known a synthetic indicator of the track or standard deviation of vertical inequality. The application of the synthetic index of the state of the tracks supported by the fact that it includes three geometric parameters, that change during the repair of the track, i.e. the vertical and horizontal inequalities, and twist. The advantage of standard deviation is the ease of its relationship with the speed of trains. An example of regressive-correlation relationships between a synthetic indicator of the state of the track and the standard deviation is the relationship (5) obtained from the measurements of track section exploited (Fig. 1) within six months after its construction.

$$
\bar{J}=0,89 S_{J}+0,08, r=0.86
$$




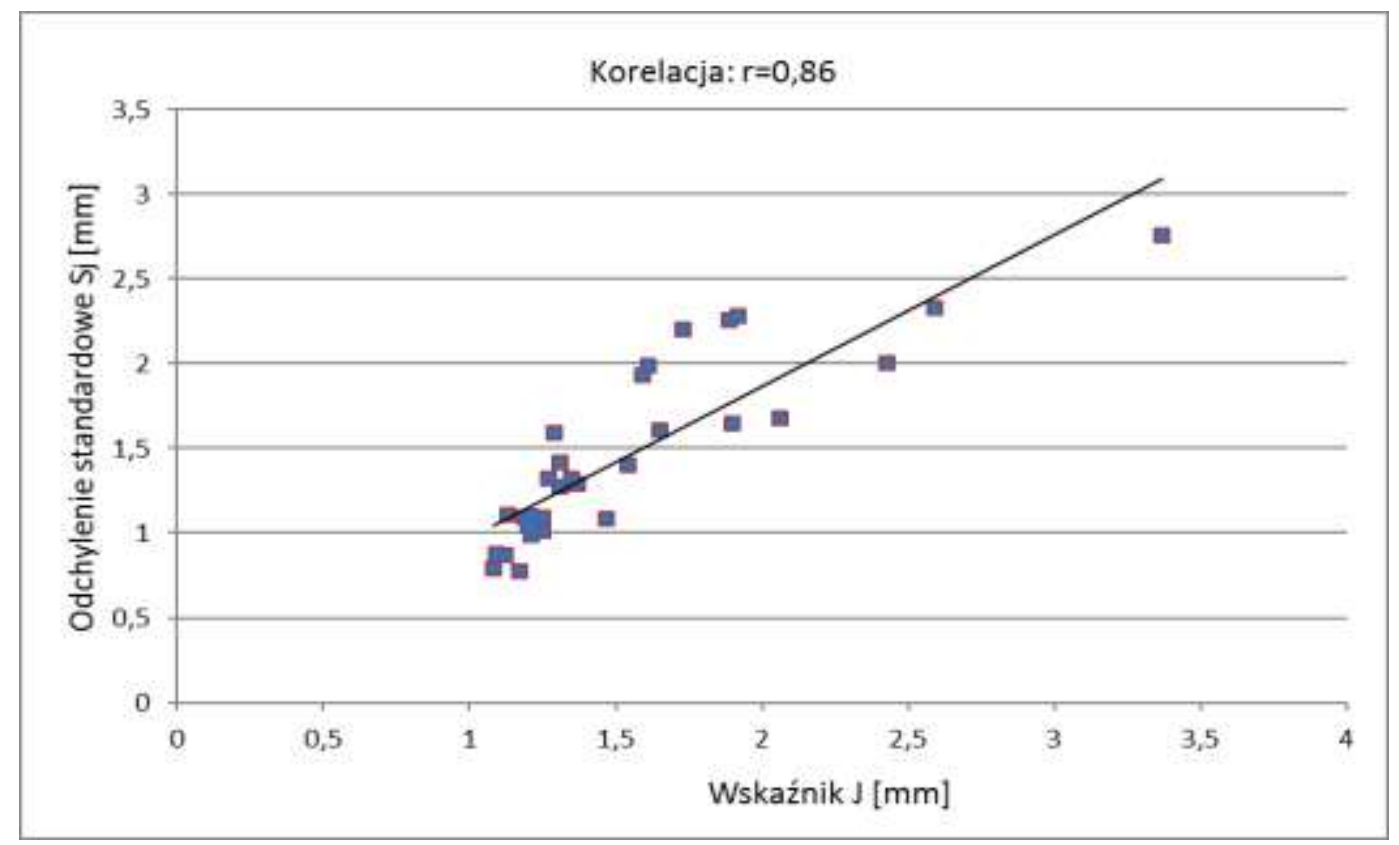

1. Relationship between index $J$ and the standard deviation of vertical inequality $S_{j}$.

\section{Outline of the methods of forecasting}

We know of at least three divisions of forecasting methods. The first possibility is heuristic methods based on experiences and sometimes described only linguistically. The second group includes methods based on the collection of data on specific objects. They use models are known from mathematical statistics and operational research. The third group contains methods based on models describing the durability and damages of specific objects or devices. There are recommendations for heuristic methods connecting the three types methods, especially to determine the survival time (RUL - Remaining Useful Live).

A division based on used techniques is the division of forecasting methods into mathematical-statistical methods (quantitative) and non-mathematical, i.e. mainly qualitative (heuristic), which uses data on existing processes and expert knowledge. These divisions are further developed and the mathematical-statistical methods are further divided into deterministic and econometric models.

Forecasts are also divided in terms of temporal scope. In the short-term forecasts it is assumed the existence of only quantitative changes. Medium-term forecasts refer to the period in which the quantitative changes occur and, optionally, a small amount of qualitative changes. The long-term prediction refers to a time in which occur quantitative and qualitative changes. You can also meet other division, in which the only time is a border, whereas the limits of short-term forecasts are assumed 4 months, and for medium- and long-term two years and over two years, respectively.

\section{The essence of forecasting geometric changes}

Empirical time series of above-mentioned measures, obtained from geometric measurements performed with measuring trolley or electronic track measure devices are suitable to describe the changes in geometric state of superstructure. These series have a short length. For example, for repairs in the two-year cycle and two measurements per year, the time series describing the change regardless of the length of a trail or a longer track section, that is, the number of members, consist of only four sets of values. This regularity required development of an original method of forecasting.

The aim of the projections is not in this case, the delimitation of the time series, i.e. extracting regular fluctuations resulting from the long-term trend of development, cyclical 
basis or irregular fluctuation, but the acquisition of quantitative information about the state of the track after a certain time. Short time series in fact limit the application of only smoothing moving average, which is not recommended even for longer series [7]. The usefulness of the average rate of changes, which is the geometric smoothing [8], is also limited

$$
\hat{y}_{g}=n-1 \sqrt{\frac{y_{n}}{y_{1}}} .
$$

This value is therefore dependent only on the first $y_{1}$ and the last $y_{n}$ member of time series and does not lead to any quantitative forecast.

Under these conditions, the averaging calculation of two models was adopted for the construction of forecasting. The first model is based on the calculation of regressivecorrelation relationship between $J_{i}$ and its next value $J_{i+i}$

$$
J_{k(i+1)}=\alpha J_{i}+\beta, r
$$

where $\alpha$ and $\beta$ characterize a regression equation, $r$ is the correlation coefficient This relationship is used for the forecasting in the third and subsequent periods of measurements, i.e. the calculation of indices $J_{p(i+2)}$

A relationship between the synthetic indices of the state of the track on the same stretch from different periods of measurement is usually quite large and often higher when the state of the track is good. It is visible in Figure 2, where the track on the section from $\mathrm{km} 37$ to 64 is much better than on the section from $\mathrm{km} 15$ to 36 . For the entire length, i.e. from 15 to $64 \mathrm{~km}$, the correlation coefficient was 0,96 , whereas big differences between successive measurements were only on 2 kilometres (Fig. 3).

The second model includes moving average, wherein the prediction of the third period consists of two members

$$
\widehat{J}_{3}=\frac{J_{1}+J_{2}}{2} .
$$

In the fourth and subsequent cycles, the second model will have a form of the arithmetic average from the last three measurements

$$
\widehat{J}_{i+1}=\frac{J_{i}+J_{i-1}+J_{i-2}}{3} .
$$

The result of the calculation in a specific kilometre of a track will be projected value

$$
J_{p i}=\frac{J_{k i}+\widehat{J}_{i}}{2}
$$




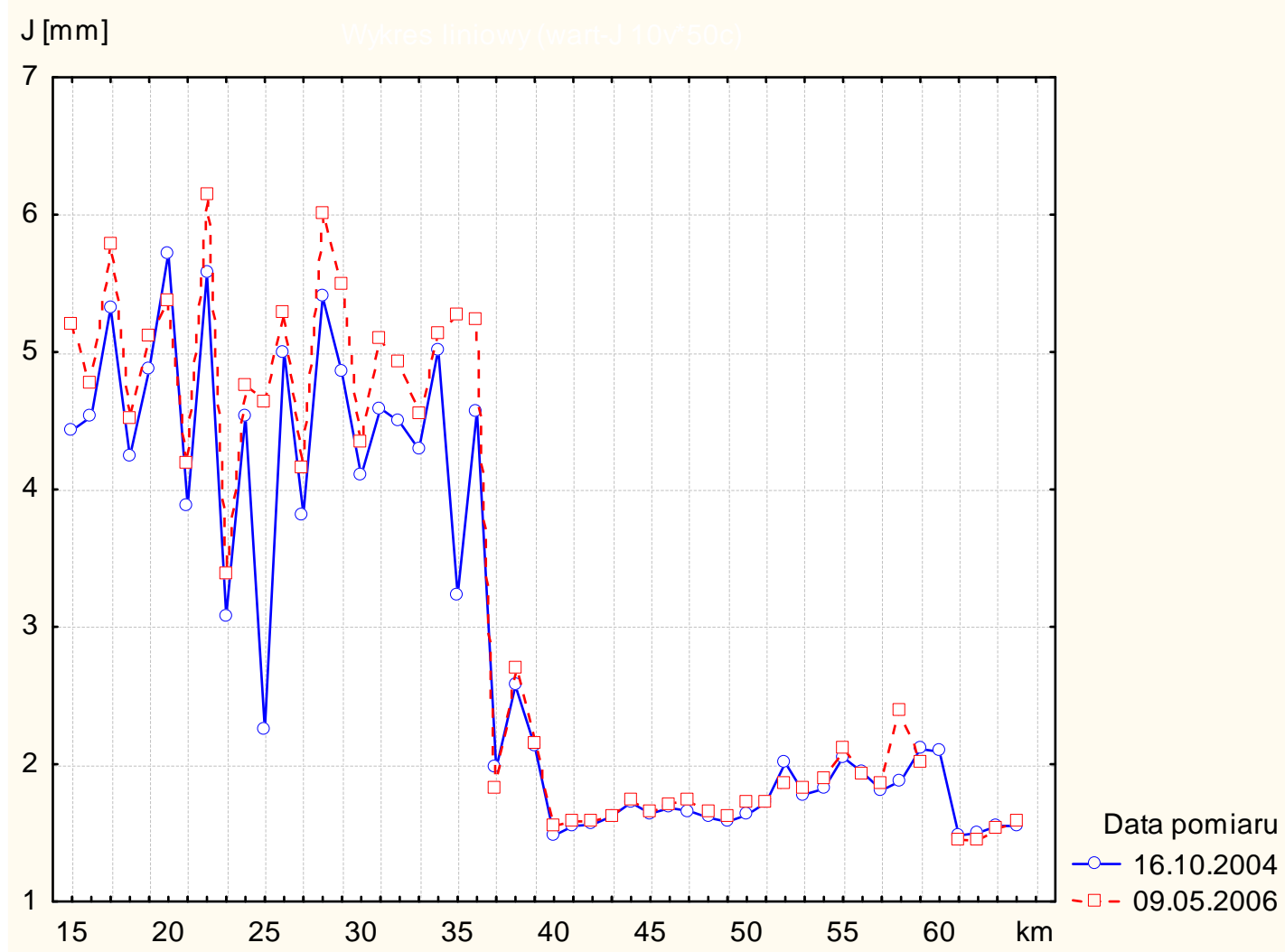

2. Values of synthetic indices of track state from two measurements (from [4]).

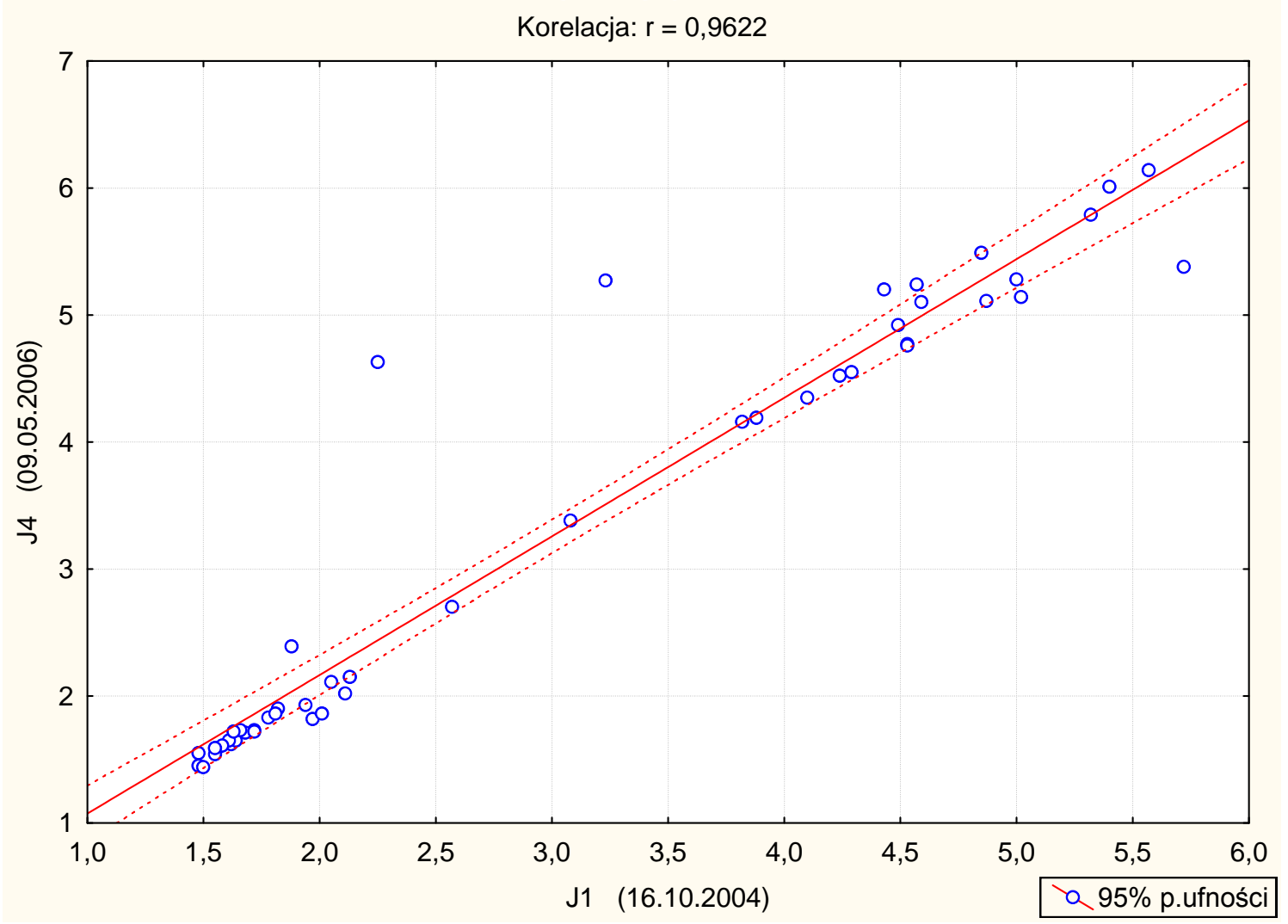

3. The relationship between the synthetic indices of track state shown in Figure 2. (from [4]). 


\section{Example calculations}

On a particular route with a length of $8.237 \mathrm{~km}$, calculated synthetic indices $J$ after 6 months after the last boost were as shown in Table 1 . They are a part of a section covered by the forecasting with the length of $47 \mathrm{~km}$.

From the 8-kilometer route two extreme kilometres were rejected, where values of indices $J$ deviated substantially from the other because of turnouts.

Between the first and second measurement on the section covered by the forecast, i.e. on the length of $47 \mathrm{~km}$, we obtained a relationship, which determines the component of prediction in the third period

$$
J_{k 3}=1,22 J_{2}-0,09, r=0,75
$$

while between the second and third measurement

$$
J_{k 4}=1,08 J_{3}+0,24, r=0,64
$$

Between the third and the fourth measurement the relationship is

$$
J_{k 5}=1,25 J_{4}+0,10, r=0,58 .
$$

Table 1. Example calculations for the 6-kilometer stretch covered by forecasting

\begin{tabular}{|c|c|c|c|c|c|c|}
\hline Measure J [mm] & 134 & 135 & 136 & 137 & 138 & 139 \\
\hline \begin{tabular}{c}
\hline$J_{1}$ \\
from the first measurement
\end{tabular} & 2,57 & 2,14 & 2,06 & 1,08 & 1,59 & 1,92 \\
\hline \hline $\begin{array}{c}\mathrm{J}_{2} \\
\text { from the second measurement }\end{array}$ & 3,38 & 2,97 & 2,10 & 1,11 & 1,64 & 2,00 \\
\hline $\begin{array}{c}\mathrm{J}_{\mathrm{k}} \\
\text { between the measurements 1.and 2. }\end{array}$ & 4,03 & 3,53 & 2,47 & 1,26 & 1,91 & 2,35 \\
\hline $\begin{array}{c}\hat{\mathrm{J}}_{3} \\
\text { moving average from 1. and 2. } \\
\text { measurements }\end{array}$ & 2,98 & 2,56 & 2,08 & 1,10 & 1,62 & 1,96 \\
\hline $\begin{array}{c}\mathrm{J}_{3} \\
\text { predicted value } \\
\text { for 3. measurement }\end{array}$ & 3,50 & 3,04 & 2,28 & 1,18 & 1,76 & 2,16 \\
\hline $\begin{array}{c}\mathrm{J}_{3} \\
\text { from the third measurement }\end{array}$ & 3,63 & 3,12 & 2,30 & 1,27 & 1,83 & 2,20 \\
\hline $\begin{array}{c}\mathrm{J}_{\mathrm{k}} \\
\text { between the measurements 2. and 3. }\end{array}$ & 4,16 & 3,61 & 2,72 & 1,61 & 2,22 & 2,62 \\
\hline $\begin{array}{c}\hat{\mathrm{J}}_{4} \\
\text { moving average z 2. and 3. } \\
\text { measurements }\end{array}$ & 3,19 & 2,74 & 2,15 & 1,15 & 1,69 & 2,04 \\
\hline $\begin{array}{c}\mathrm{J}_{\mathrm{p}} \\
\text { predicted value } \\
\text { for 4. measurement }\end{array}$ & 3,68 & 3,18 & 2,44 & 1,38 & 1,95 & 2,33 \\
\hline \hline $\begin{array}{c}\mathrm{J}_{4} \\
\text { from the fourth measurement }\end{array}$ & 2,46 & 1,31 & 1,96 & 2,35 \\
\hline \hline
\end{tabular}




\begin{tabular}{|c|c|c|c|c|c|c|}
$\begin{array}{c}\mathrm{J}_{\mathrm{k}} \\
\text { between the measurements 3. and 4. }\end{array}$ & 4,69 & 4,03 & 3,18 & 1,74 & 2,55 & 3,04 \\
\hline $\begin{array}{c}\hat{J}_{5} \\
\text { moving average z 2., 3. and 4. } \\
\text { measurements }\end{array}$ & 3,56 & 3,08 & 2,29 & 1,23 & 1,81 & 2,18 \\
\hline $\begin{array}{c}\mathrm{J}_{\mathrm{p}_{5}} \\
\text { predicted value } \\
\text { for 5. measurement }\end{array}$ & 4,12 & 3,55 & 2,73 & 1,48 & 2,18 & 2,61 \\
\hline \hline
\end{tabular}

\section{Conclusions}

Methods of forecasting changes in railway superstructure cover a much wider range of issues than are addressed in this work. Apart from forecasting structural changes, it is worth noting that the relevant details in predicting changes in the geometric state, not recognized here, include methods of long-term forecasts, the evaluation of forecast errors, the algorithm of transition from the forecast to a decision about the need to repair, the automation of the calculation and presentation of results, and several others.

Comprehensive elaboration of this issue still requires many studies that are already underway. Their results will be a general method, which may significantly affect the rationalization of expenditures on repair superstructure, and so the most important component of the cost of its lifecycle.

\section{Source materials}

[1] Bałuch H.: Kryteria określania kolejności napraw nawierzchni kolejowej. IV Seminarium Diagnostyczne, maj 2002.

[2] Bałuch H.: Planowanie szlifowania szyn w torach kolejowych. Transport i Komunikacja 2008, nr 5.

[3] Bałuch H. Rankingowa kwalifikacja torów do profilowania szyn. X Konferencja „Nowoczesne Itechnologie i Systemy Zarządzania w Transporcie Szynowym”, Zeszyty NT. SITKRP Oddział Kraków nr 96 (158), 2013.

[4] Bałuch M.: Ocena zakresu robót nawierzchniowych z zastosowaniem systemu Sohron na przykładzie odcinka linii Zielonka-Białystok. Praca CNTK. temat 3072/11, Warszawa 2007.

[5] Dingqing L., Holder J., Dwight C.: Implementing a tie degradation model for maintenance planning. Railway Track and Structures 2007, No 3.

[6] Eker O.F. et al.: A simple static-based prognostic model for railway turnout systems. IEEE Transaction on Industrial Electronics, 1019, vol 58, issue 5.

[7] Hryniewiecki O.: Wykłady ze statystyki. Wyższa Szkoła Informatyki Stosowanej, Warszawa 2000.

[8] Luszniewicz A., Słaby T.: Statystyka z pakietem komputerowym STATISTICA ${ }^{\mathrm{TM}}$ PL. Teoria i zastosowania. Wydawnictwa C,H. Beck, 2001.

[9] Schafer D.H.,Barkan C.P.I.: A prediction model for broken rails and an analysis of their economic impact. Proceedings of AREMA Conference, 2008.

[10] Tanaka H., Sano K., Miwa M.: Growth of rail corrugation and its prediction model. 13th International Conference Rail Engineering, Edinburgh, 2015.

[11] Volk W.: Statystyka stosowana dla inżynierów. Wydawnictwa Naukowo Techniczne, Warszawa 1973. 